\title{
Reconfiguración de los imaginarios poéticos del archipiélago de San Andrés, Providencia y Santa Catalina: los relatos de Lenito Robinson-Bent y Juan Ramírez Dawkins ${ }^{1}$
}

\author{
Ana Elena Builes Vélez ${ }^{2}$ \\ Universidad Pontificia Bolivariana (Colombia) \\ ORCID ID: 0000-0002-9655-8193 \\ Melissa Pérez Peña ${ }^{3}$ \\ Universidad Pontificia Bolivariana (Colombia) \\ ORCID ID: 0000-0002-1605-202X
}

Recibido: 11 de abril de 2019

Aceptado: 24 de mayo de 2019

"A pesar de los esfuerzos, los tesoros y el tiempo invertidos la Corona Española no consiguió la homogenización soñada; tampoco lo lograron sus contemporáneos

Francia e Inglaterra".

Álvaro Howard

"Escuchar los países detrás del islote. Desde el punto fijo de aquí, tejer esta geografía".

Edouard Glissant

\section{RESUMEN}

Los imaginarios del archipiélago de San Andrés, Providencia y Santa Catalina han estado comúnmente reducidos a la industria hotelera y al turismo, invisibilizando una serie de tradiciones, realidades, emociones, percepciones y vivencias diarias de los pobladores de este territorio. Ante este acallamiento, se unen las voces de los escritores de las islas para permitir, a partir de su apuesta poética, tejer una visión más polifónica y menos estática. Se estudiaron cuatro relatos de los escritores Lenito Robinson-Bent y Juan Ramírez Dawkins, de la isla de Providencia, Colombia, con el propósito de evidenciar los imaginarios del archipiélago emanados desde las propias islas. Para esto se realizó una caracterización del Caribe, un rastreo de los autores del archipiélago y finalmente el análisis de los cuentos de los autores seleccionados.

Palabras clave: archipiélago, imaginarios, Caribe, Lenito Robinson-Bent, Juan Ramírez Dawkins

\footnotetext{
${ }^{1}$ Reconfiguration of the Poetic Imaginary of the Archipelago of San Andrés, Providencia and Santa Catalina: The Stories of Lenito Robinson-Bent and Juan Ramírez Dawkins

${ }^{2}$ Magister en Diseño, gestión y ejecución de proyectos, Universidad Internacional Iberoamericana. Coordinadora de Posgrados e Investigación, Escuela de Arquitectura y Diseño. Universidad Pontificia Bolivariana, Medellín. Grupo de Investigación Lengua y Cultura. Correo electrónico: ana.builes@upb.edu.co

${ }_{3}^{3}$ Profesional en Estudios Literarios, Universidad Pontificia Bolivariana. Correo electrónico: melissape.96@gmail.com
} 


\section{ABSTRACT:}

The imaginaries of the archipelago of San Andrés, Providencia and Santa Catalina have been commonly reduced to the hotel industry and tourism, making invisible a series of traditions, realities, emotions, perceptions and daily experiences of the inhabitants of this territory. Before this silencing, the voices of the writers of the islands join to allow, from their poetic commitment, to weave a more polyphonic and less static vision. Four stories by the writers Lenito Robinson-Bent and Juan Ramírez Dawkins, from the island of Providencia, Colombia, were read with the purpose of highlighting the imaginary of the archipelago from the islands. For this, a characterization of the Caribbean was made, a tracing of the archipelago's authors and finally the analysis of the stories of the selected authors.

Key words: archipelago, imaginaries, Caribbean, Lenito Robinson-Bent, Juan Ramírez Dawkins

\section{INTRODUCCIÓN}

La poetización caribeña no solo ahonda en los paisajes de la abundancia perceptibles desde la playa, que no es solo un lugar de tránsito, de goce y de olvido, sino que encierra en su interior, de una forma densa como sus bosques, las heridas de la historia, el dolor de los llegados y de aquellos que desde la orilla ven partir sus anhelos, que también es lugar de memoria y, por tanto, de nostalgias y dolores. Ahora, el personaje principal deja de ser Ulises, para cederle la luz a Circe. El arquetipo del marinero, del viajero que vaga de isla en isla, pasa de ocupar el lugar central para que la historia sea contada por el que espera, aquel que brinda su hogar y despide desde el puerto. Es el turno del narrador nativo.

En este trabajo nos preguntamos por la participación de las islas del Caribe colombiano en la creación de mundos conocidos e imaginarios que terminan en una problematización entre la historia, la memoria y la identidad. La pregunta inicial fue ¿qué escriben en la isla? Entender de qué manera esta literatura se hace "partícipe en la construcción de imaginarios, símbolos de identificación y reconocimiento de las islas", como de la identidad y la memoria de esta región (Acosta, 2007: 164). Sin embargo, existe una dificultad evidente en el rastreo de estas obras, toda vez que, entre las historias regionales de la literatura, la zona insular colombiana es minimizada, invisibilizada y casi borrada del mapa historiográfico en relación con su producción literaria. El reconocimiento de la literatura del archipiélago de San Andrés, Providencia y Santa Catalina -reconocida como una isla desde lo geográfico, pero como tres diferentes desde su contexto histórico- se ha visto afectado por la visión centralista de gran parte de la crítica literaria del país (Tulcan, 2016).

El objetivo de este trabajo es analizar cómo la representación narrativa de la experiencia insular del Caribe colombiano, particularmente del archipiélago de San Andrés, Providencia y Santa Catalina, contrasta con los imaginarios trazados sobre estas islas luego de los diferentes procesos de colonización -inglesa, española y posteriormente los sucesos de colombianización- que atravesó el territorio, a través de las lecturas analíticas de narradores del archipiélago. Los autores que se analizan son Lenito Robinson-Bent, con algunos relatos de sus libros Las casas huidizas y 
otros cuentos sobre fugas (1994) y Sobre nupcias y ausencias y otros cuentos (2010), publicados en español, y Juan Ramírez Dawkins, con su libro Short Stories, the Soldier dem de Come and the Mango Tree publicado en 1996, los cuales se encuentran en una edición bilingüe en español y en inglés con una mezcla de kriol. Estas obras tienen una condición particular como producción insular en la medida en que no solo fueron escritas por narradores nativos del archipiélago, escritores raizales, sino también que han tenido poca difusión y escasa visibilidad, siendo tan marginales como la propia lengua kriol. ${ }^{4}$

La estética particular de estas obras y su estructura textual desafían los estándares estéticos y lingüísticos de la literatura producida en la Colombia continental que sigue siendo monolingüe y centralizada. Por otro lado, la concepción de creolidad de los teóricos Jean Bernabé, Patrick Chamoiseau y Raphael Confiant, en su libro Elogio de la Creolidad, permite comprender que lo kriol no solo se reduce a un aspecto lingüístico, sino que abarca diferentes manifestaciones culturales caribeñas, incluyendo su visión de mundo y la forma en la que atraviesa todos los ámbitos sociales en esta zona. Esto se conjuga y contrasta con las imágenes del Caribe ya construidas, que estudia Antonio Benítez-Rojo en La isla que se repite, también en las concepciones del nobel Derek Walcott, en algunos de sus ensayos publicados en el libro La voz del crepúsculo, y en algunos fragmentos del Discurso Antillano de Edouard Glissant.

\section{El Caribe insular. Un meta-archipiélago culturalmente diverso}

Pensar el Caribe insular obliga a entender una multiplicidad de experiencias de migración y destierro, que en ocasiones han sido compartidas por diferentes naciones o territorios. Es quizás por esto que Glissant en su Discurso del Caribe propone la poética de la relación, con la que es posible describir, narrar si se quiere, la experiencia caribeña como la de un conjunto de países que se han formado gracias al intercambio compartido y continuo de culturas y poblaciones (Glissant, 2002: 139). Definido como meta-archipiélago por Benítez-Rojo, el Caribe se reconforma constantemente y se construye desde la imaginación (1998: 14). Los imaginarios del Caribe se han conformado desde múltiples perspectivas. La que ahora nos interesa es aquella mirada del Caribe desde dentro, desde las islas que componen este meta-archipiélago, cuya historia ha estado acompañada de resistencias y nuevas miradas. En este mismo sentido, para Graciela Maglia, el Caribe siempre se ha resistido a una comprensión desde "las definiciones coloniales, el Caribe emerge en una ola rebelde que se vuelca en nuevas playas de la memoria” (Maglia, 2017: 91).

La historia colonial y postcolonial del Caribe se caracteriza por una serie de migraciones y desplazamientos que propiciaron un intercambio poblacional interno y externo, lo que a su vez generó mestizajes, alienaciones, y mezclas culturales y lingüísticas en las islas, que han propiciado nuevas maneras de ver y entender el mundo desde estas. Diversas discusiones académicas han buscado entender la relación presente entre los conceptos de nación y territorio. Graciela Maglia (2017), Mary Giraldo en su texto sobre La Ceiba de la memoria y Eliana Uribe, entre otros autores y autoras

\footnotetext{
${ }^{4}$ La palabra kriol es la forma escritural que se reconoce con mayor fuerza en el Archipiélago para referirse a la lengua allí hablada. Por su parte, el creole y la creolidad es la versión del francés que, en este caso, hace referencia directa al concepto propuesto por Bernabé, Chamoiseau y Confiant (2011). Decidimos mantener esa diferenciación.
} 
que se han acercado a esta temática, plantean que, en algunos casos, la nación es una comunidad limitada, soberana e imaginaria.

Las construcciones de imaginarios de lugar en el Caribe han sido el resultado de estos procesos migratorios y de deslazamiento forzado que, como consecuencia, evidencian una alienación de la visión del sujeto caribeño y una crisis de la autoimagen. Estas migraciones traerían consigo traslados culturales y sociales desde África, principalmente, pero también de Europa y de la América continental. Esto, además, generó en el sujeto del Caribe un desarrollo de la identidad transnacional, que como describe Maglia está "[...] atada a su paisaje atravesado de horizontes, en un contrabando perpetuo de lenguas, etnias y fronteras" (Maglia, 2017: 91).

En el Caribe, el territorio y sus fronteras, así como la identidad, pasan a ser categorías imaginarias casi de igual modo como el discurso nacional en el que están inscritas, como por ejemplo en el archipiélago de San Andrés, Providencia y Santa Catalina. Esto hace posible una lectura de la cultura caribeña desde los límites internos y externos que se han ido construyendo. A partir de estos se podrían comprender las maneras como las diferentes comunidades, -incluyendo los raizales del Archipiélago- basan la representación de su interacción cultural en esos múltiples desplazamientos, que han generado "una multiplicidad de comunidades en negación y pugna que define la historia del nacionalismo moderno" (Martínez, 2003: 32).

Algunos teóricos aseguran que la larga historia de interacciones entre varios grupos étnicos generó una serie de características físicas y sociales repetidas, y un desenfoque de las fronteras de los mismos grupos. En las sociedades caribeñas, lo que podría ser conocido como un grupo de límites y fronteras es parte de un sistema cultural mucho más amplio en el cual las transformaciones ocurren de manera rutinaria. La capacidad de ajuste y adaptación de estas sociedades es un elemento clave de su sistema y los habitantes nativos están acostumbrados a la aparición de símbolos culturales que parecen ambiguos al turista o extranjero, sólo porque su significado cambia de acuerdo con el contexto social en el que se muestra.

En el Caribe en que se habla español, el sentido de identidad nacional está basado menos en la raza y más en la lengua, religión y otros aspectos heredados de la cultura española. El Caribe acoge, abraza y absorbe disparidades, contradicciones e incongruencias de manera dolorosa y efectiva, tal como lo hacen otras áreas culturales en el resto del mundo. Una región reconocida como área cultural puede aceptar ser representada a través de múltiples metáforas. Sin embargo, es posible decir que ninguna metáfora contiene en este ámbito tantas capas de significación como las que serían necesarias para reconocer y expresar la multifacética experiencia que es el Caribe. Para representar la región en toda su complejidad sería necesario una imagen amalgamada, una metáfora compuesta que referencie todas las coexistencias contemporáneas de los múltiples signos. Pensar ese meta-archipiélago como un todo, posibilita un análisis más amplio: hay muchos Caribes dentro del Caribe, tantas islas como en cualquier rompecabezas complejo. Sin embargo, a pesar de la multiplicidad de formas individuales, todas hacen parte de una estructura dentro de un esquema regional más amplio, y las características sociales y culturales de cada una forman una identidad completa y elaborada del Gran Caribe. 
Ana Elena Builes Vélez - Melissa Pérez Peña

El archipiélago de San Andrés, Providencia y Santa Catalina está situado entre los confines solitarios de las islas que lo constituyen y el territorio expansivo de la tierra firme hacia la cual de alguna manera siempre está apuntando, relacionándose entre sí, mientras cada territorio mantiene su propia identidad distintiva. En el Archipiélago es posible observar complejas y ambivalentes relaciones que interactúan caóticamente, dando forma a una particular sociedad en la que convergen múltiples lenguas, culturas y religiones, y de la cual surgen múltiples producciones artísticas y literarias que casi nunca salen del archipiélago.

La cultura, en particular la literatura como institución, tiene un vínculo muy estrecho con la consolidación de una identidad nacional. La constitución de un corpus definido a partir de la migración y el desplazamiento no puede llevarse a cabo sin tomar en cuenta la filiación histórica de la producción simbólica con una determinada identidad colectiva. La producción literaria del meta-archipiélago se reconoce bajo el concepto de "literatura caribeña", el cual recoge un corpus de escritos de las diferentes islas del Caribe, una región que contiene diversas naciones y lenguas, varias manifestaciones políticas y diferentes religiones.

III. Rastreo de autores y obras del archipiélago de San Andrés, Providencia y Santa Catalina Al acercarnos a la producción intelectual de las islas de San Andrés, Providencia y Santa Catalina hallamos la necesidad de comprender algunos panoramas sociales y políticos que han permeado, no solo las temáticas de los textos producidos, sino también las condiciones y posibilidades de publicación y divulgación de dichos productos culturales. De esta forma, debemos tener claro algunos hechos históricos que marcaron la vida de los habitantes de las islas. El primero es el hecho de que su poblamiento fue en su gran medida por ingleses y sus esclavizados, marcando un hito diferenciador frente al Caribe continental colombiano (Clemente, 1994: 331) y estrechando lazos con otras islas de las Antillas, como por ejemplo Jamaica.

Esta notable distancia de los pobladores del archipiélago respecto a los continentales se intensificó con la visita en 1953 de Gustavo Rojas Pinilla, el primer presidente colombiano que viajó a San Andrés. Rojas Pinilla declaró la isla como de interés turístico, decretando medidas urgentes que permitieran su reconquista cultural y suprimieran el sentimiento de lejanía de sus pobladores respecto al país al que pertenecían. De este modo se dio inicio a un movimiento de "colombianización", implementado a través de una política pública denominada "Puerto libre" (Clemente, 1994: 349). Esto desencadenó una migración masiva de personas provenientes del interior de Colombia, al igual que de otras nacionalidades como sirios y libaneses, que impactaron de diversas formas la organización social y cultural de este territorio. El plano geográfico se vio dividido de tal forma que el norte, North End y Sarie Bay, al igual que su actividad comercial, pasaron a manos de los inmigrantes y los sectores de la Loma y San Luis quedaron a manos de pobladores raizales quienes se desempeñaban principalmente como agricultores (Clemente, 1994: 350).

Esta política pública afectó también de manera considerable aspectos culturales de las islas, no sólo por el gran incremento de los movimientos migratorios, sino porque también tuvo grandes modificaciones en materia de educación. Esta fue entregada a la Iglesia Católica, desplazando 
grandes instituciones cristianas ya instauradas como la adventista y en especial la bautista. A su vez, el español fue impuesto como única lengua en el ámbito escolar, segregando el idioma kriol y todo el acervo identitario de los raizales. ${ }^{5}$ Debido a la instauración de la política pública, el pueblo raizal comenzó a perder progresivamente la práctica de su lengua materna o a utilizarla solamente como medio de comunicación en el interior de su comunidad. Esto trajo consigo aspectos positivos tales como la posibilidad de manejar un código secreto cuando se trataba de tomar decisiones políticas importantes y evitar que personas externas tuvieran conocimiento de ello. Pero a su vez, al ser sólo oral y no tener una lexicografía clara, conllevó a reforzar la marginalidad del kriol, dificultando que se extendiera la producción de intelectuales preocupados por el reconocimiento de esta como una lengua oficial.

Expuestos estos antecedentes, podemos comprender algunos de los principales obstáculos con que nos encontramos al iniciar la presente investigación, es decir, la dificultad para acceder a las obras producidas en las islas. Con relación a esto, Laurence Prescott llama la atención sobre la situación precaria en que se encuentra un escritor colombiano promedio a la hora de publicar: "[...] cuanto más lejos de los grandes centros culturales se encuentra el autor, tanto más improbable que la obra se promocione, circule y se conozca no sólo fuera del lugar donde se publica, sino también fuera del país" (Prescott, 1996: 112-113). Si a este aislamiento geográfico le sumamos el rechazo del público continental por las costumbres de origen inglés anteriormente mencionadas y la inmanente oralidad del kriol, encontramos que la mayoría de los escritores del archipiélago no logran circular fuera del ámbito insular.

Mónica María del Valle, en su texto "Perspectivas críticas sobre la literatura en San Andrés Isla, Colombia", realiza una investigación exhaustiva sobre el panorama literario de este territorio, encontrando que la política y la necesidad de autoidentificación se postulan como leivmotiv en la gran parte de esa producción: "[...] la visibilidad de algunos escritores como la invisibilidad de otros, tanto la escritura en creol como la escritura en español, y la elección de uno u otro tipo discursivo, se aclaran en razón de esta doble articulación de San Andrés como isla con su vida propia y San Andrés como departamento de ultramar colombiano" (2016: 192-193). Es por esto que cualquier elección sobre la forma de publicar, el idioma en el cuál hacerlo, los temas y los medios, están atravesados por condicionantes sociales, políticos y económicos que coexisten en el territorio insular. Ante esta problemática, Del Valle realiza una clasificación de los escritores más divulgados en las islas y fuera de ellas, separándolos en tres grandes grupos. ${ }^{6}$ Finalmente, Del Valle, llama la

\footnotetext{
${ }^{5}$ Según plantea J. Botero: "El creole es una lengua oral -es decir, que no posee un sistema de escritura alfabética- de base akán y lexicalizada en inglés, que históricamente ha sido discriminada por el Estado colombiano por ser un 'inglés mal hablado' y por diferenciar a sus hablantes del resto de la población colombiana al no hablar español como lengua materna" (2007: 279).

${ }^{6}$ En el primero se encuentran aquellos que tienen un reconocimiento notorio, tales como los que se incluyeron en la colección de literatura afro colombiana del Banco de la República como Hazel Robinson, Lenito Robinson-Bent, Juan Ramírez Dawkins, Lola Pomare-Myles y algunas poetas como son Margarita Benet Robinson, Briceña Corpus Stephens, Emiliana Bernard Stephenson, Herminia Macariz Michell y Marqueta McKeller. A este grupo pertenecen también escritores más contemporáneos como Keisha Howard, Alciano Williams y Adel Christopher. En un segundo grupo se encuentran escritores que no son propiamente intelectuales raizales, tales como los primeros, pero que habitaron la isla en algún momento de su vida y abordan de una u otra forma algunas de las problemáticas de la región: Claudia Aguilera, Nadim Marmolejo, Lina Chow Wong, Claudine Bancelin, Mariamatilde Rodríguez, Jorge Muñoz, Franco Grittani, Fanny Buitrago, entre otros. Si bien los pertenecientes a este grupo pueden llegar a ser conocidos, en especial en el interior del país, suelen ser de poca difusión y los ámbitos donde más se les encuentra es en pequeños círculos de lectores (Valle, 2016: 189).
} 
atención sobre las particularidades del tercer grupo, ya que corresponde a aquellos intelectuales que son considerados como escritores de profesión al interior de su comunidad, pero que por las características antes mencionadas del carácter primariamente oral del kriol, la censura de la cultura inglesa de los isleños y la falta de oportunidades para la difusión, no suelen ser publicados y circulan solamente en ámbitos cercanos:

[...] pero los textos no están agrupados ni circulan para el público en general. Pasan de manos del escritor o escritora a manos de sus amigos, y de ahí a manos de los conocidos de los amigos en una cadena que se puede alargar [...] Las plagas humanas bestializadas (s.f.) y Meditamos con tristeza el abismo de nuestras tinieblas (2011) y Con cara ganan los Tomatodo...con sello pierde el pueblo... todo para ellos; todo para ellos (2012), entre otros, de Eviston Forbes Bernard, conocido como "Papalee"; y A oscuras pero encendido (2001), Legado de piratas (2006) y, en menor medida, Meridiano 82, la ruta de la langosta (2010), de Jimmy Gordon Bull (Valle, 2016: 190).

Como enunciábamos anteriormente, una de las imposibilidades que encontramos al acercarnos a este objeto de estudio, fue la dificultad de acceder al material publicado dadas las referidas condiciones de divulgación y publicación. Es por esta razón que nos centramos en las obras de Lenito Robinson-Bent y Juan Ramírez Dawkins, ya que no sólo escriben en un periodo cronológico cercano, sino que, además, son a las que accedimos para su lectura y análisis.

\section{Lenito Robinson-Bent: la poética del mar y la ritmicidad del paisaje, elementos de la literatura kriol}

Al momento de acercarnos a la escritura narrativa de Lenito Robinson-Bent encontramos que se dificulta disociar la experiencia vital del hombre de mar de la poética que rodea la construcción de sus relatos. ${ }^{7}$ El extrañar a su isla desde lejos, le hace reconfigurarse la idea que tenía de ella, comienza a percibirla desde la mirada del que parte y rememora desde lejos, pero a su vez, les ofrece a sus personajes la voz de aquel que permanece en el puerto después de que el barco zarpa, comprendiendo que la nostalgia tiene dos polos a tierra, tal como refiere Claudine Banceline:

Partió porque quería conocer el mundo como lo hacían muchos hombres isleños, solo que ellos se iban en veleros hacia puertos sin nombre [...] Fue allí -cuando se le vino la isla encima, con todos sus recuerdos, con todas las nupcias contrariadas y con todas las ausencias- donde escribió entonces la mayoría de los cuentos de este volumen, mientras transcurría 1984 preparaba un posgrado en Literatura Francesa (2010: 9).

Para observar estos planteamientos con mayor detenimiento, revisaremos los cuentos "Regreso al alba" del libro Las casas huidizas y otros cuentos sobre fugas (1994) y "Divagaciones para una carta a Nereida

\footnotetext{
${ }^{7}$ Para comprender mejor las intercepciones entre vida y obra, debemos recurrir a algunos datos biográficos del autor. Robinson-Bent nace en la Isla de Providencia, municipio de San Andrés, en 1956. Termina sus estudios de bachillerato y guiado por su pasión hacia las letras, este hombre caribeño decide partir a las frías tierras cundiboyacenses donde ingresa a la Universidad de Tunja. Para poder pagar su carrera, comienza a dar clase de inglés, español y francés, al igual que se interesa por la traducción. Se recibe como licenciado en lenguas modernas y es en este momento donde su alma de hombre de puerto le hace embarcarse en un viaje a Francia para estudiar un posgrado en literatura francesa en Universidad de la Sorbona.
} 
del Mar" del libro Sobre nupcias y ausencias y otros cuentos (2010). Estos fueron seleccionados debido a la distancia cronológica existente entre ambos, posibilitándonos identificar cambios o permanencias de elementos narrativos y estilísticos del autor. Además, nos permiten esbozar una relación de apropiación del territorio, en especial del mar, desde diferentes perspectivas, logrando trazar un cuadro comparativo entre los imaginarios que se han construido del Caribe desde afuera, desde una visión colonial, y aquellos que son manifestados por sus habitantes.

Como vimos con anterioridad, el territorio de San Andrés y Providencia es un espacio álgido en cuestiones políticas e identitarias, lo que conlleva a que cualquier decisión que asuma un autor en estas islas, aunque se presuma enteramente estética, trae consigo la necesidad de reflexionar y repensar el posicionamiento de este frente a las condiciones que le circundan. En este caso en específico, Robinson-Bent decide apropiarse de las diferentes influencias europeas que permearon su vida, tal como lo es la escritura en español, elemento justificable en la necesidad de difusión fuera de la isla, que la marginalización del kriol no le habría permitido. No obstante, no es Europa la que se dibuja en sus cuentos, es el latir del Caribe el que guía su pluma y es por esta razón que podemos aventurarnos a clasificar a este autor y su obra dentro de la narrativa kriol.

Debemos llamar la atención acerca de la necesidad de interconectar las particularidades de este pequeño archipiélago colombiano con el Gran Caribe, el meta-archipiélago de Benítez-Rojo, cuyas relaciones, a pesar de no lograr ser definidas con claridad, se centran en la convergencia y similitud de los procesos históricos, acontecidos en todos los territorios que lo forman, los cuales han condicionado su constitución hasta hoy día. La descentración de la identidad y el abandono de teorías esencialistas que buscan fijar y marcar sobre piedra el comienzo de los "Pueblos del mar", han permitido la abundancia de opiniones y teorías. Dentro de estas, una de las más difundidas es la propuesta por Bernabé, Chamoiseau y Confiant en Elogio de la creolidad. Estos autores entienden que aquel latir o ritmo caribeño se encuentra en su diversidad, en las diferentes formas de ser de sus pobladores, de sus historias y de sus tradiciones, elementos que reúnen bajo el título de creolidad: "La creolidad es una aniquilación de la falsa universalidad, del monolingüismo y de la pureza. Se halla en creolidad lo que se armoniza con lo Diverso" (Bernabé, Chamoiseau \& Confiant, 2011: 25).

De esta forma, la primera barrera que derrumba Robinson-Bent es aquella que considera que la creolidad se limita a aspectos lingüísticos. Es decir, que los autores que deciden expresarse en inglés, español, francés o portugués, actúan como "colonizados", desechando la idea de que el Caribe se forma en la confluencia y apropiación de estas diferentes mareas, que negar una de sus raíces sería disolver una parte importante de su constitución. Esta confluencia de herencias permite observar los diferentes matices que se funden en estos espacios y brindan casi un prisma de diversas voces. Robinson-Bent utiliza una lengua heredada de los procesos de colonización para poder acceder a un público mayor, a un espectro de gente fuera de la isla y a su vez, lograr transmitir un sentir y su propio imaginario del territorio que contrasta con aquellos tan fijos sobre los pueblos caribeños. 
Ahora bien, eso que llamamos el latir del Caribe, podemos discernirlo en dos elementos claves en la configuración de la trama narrativa de las dos obras a analizar: la importancia que cobra el mar, que nombraremos "poética marítima" y el sentimiento de nostalgia y desgarramiento. Vale la pena comenzar trayendo a colación las palabras pronunciadas por el Nobel Derek Walcott, quien logra criticar toda una idea vendida y difundida por las agencias de viaje sobre este territorio:

Por eso quienes visitan el Caribe se sienten como si habitaran en una sucesión de tarjetas postales. El clima se adapta a lo que de él hemos leído. Para los turistas, el sol no es cosa seria. El invierno confiere hondura y oscuridad tanto a la vida como a la literatura, y en el interminable verano de los trópicos ni siquiera la pobreza o la poesía -en la Antilla la pobreza, poverty, se diferencia de la poesía, poetry, apenas por una V, une vie (una vida), una condición vital además de imaginativa- parecen capaces de ser profundas, porque la naturaleza es tan exultante, tan decididamente extática como su música. Una cultura basada en la dicha es necesariamente superficial. Para venderse, el Caribe fomenta tristemente los placeres de la banalidad, de una brillante vacuidad, en tanto lugar donde no sólo es posible huir del invierno, sino también de la seriedad que provoca una cultura con sus cuatro estaciones (Walcott, 2000: 95).

El Caribe se postula de esta forma para el turista como un lugar estático y paradisíaco, donde no acontece nada realmente profundo o trascendental, y donde a su vez todo debe ser fiesta y jolgorio. Frente a esta idea lapidaria y superficial, Robinson-Bent nos ofrece una visión de una isla en la que habita la nostalgia, en la que se ahonda en la psique y en el espíritu humano a partir de la soledad: "A menudo quiero recordarte las nostalgias que nunca fueron nuestras porque las circunstancias opusieron resistencia. Por ejemplo, una despedida de abrazos y aprietos en un muelle ruidoso al alba, mientras el barco suelta amarras, y nosotros sin palabras, nos quedamos al amparo de las miradas prometedoras" (Robinson-Bent, 2010:96). Observemos cómo el puerto deja de verse como aquello que recibe, deja de ser la puerta al placer, para mostrarnos su otra faceta, la de aquel que ve partir entre llantos amores, sueños y esperanzas que se combinan con el eterno vaivén de las olas. Pero este sentimiento de nostalgia solo logra hondura a partir de la materialidad adecuada para extenderse y derramarse por las páginas: el mar. En este sentido, cobra fuerza lo enunciado por Brathwaite y Glissant:

En nuestras literaturas, el paisaje no es un decorado, sino un personaje en sí mismo. Tenemos dos variantes de paisaje. Primero, porque vinimos por mar, a través del Paso del Medio, hacia las islas, y allí imaginamos el mar, como señaló Kamau. Y, junto con esto, estábamos en el período de la esclavitud. Al decir "esclavitud" pienso en los cimarrones que huyeron hacia el bosque, hacia las montañas, para liberarse. Por tanto, nuestras ideas de libertad están vinculadas a las montañas y al mar (Glissant cit. en Phaf-Rheinberger, ed., 2007: 320).

En concordancia con esto, Robinson-Bent toma toda la fuerza creativa que le brinda el haber sido un hombre que creció y vivió en el mar, y la utiliza no solo para constituir su trama narrativa, sino incluso sus personajes y sus apreciaciones más profundas sobre el alma humana.

Contrario a los imaginarios tejidos por las empresas de turismo o la publicidad, el océano no brinda a partir de su observación una simple distracción de los pensamientos o un lugar en el 
cual refugiarse. Por el contrario, ahonda en los oscuros rincones del alma humana, inspirando la melancolía: "Ondina se sentó frente a la ventana hacia el mar, mirando el agua, juntando retazos de pequeñas imágenes volátiles, multicolores, para tratar de recordar cómo era el abuelo que ella conocía" (Robinson-Bent, 1994: 19). El mar deja de ser simple elemento de fondo, o escenario donde suceden las cosas, para ser testigo, mensajero y parte activa de la narración.

Ahora bien, estos dos extremos geográficos, el mar y la montaña, que para los teóricos del Caribe cobran tanta relevancia, ayudan a marcar la temporalidad en el cuento "Divagaciones para una carta a Nereida del Mar". Observemos como la obra se divide estructuralmente en cuatro fragmentos que se diferencian a partir de unos asteriscos, los cuales a su vez denotan una temporalidad diferente. La narración comienza con una voz en primera persona que habla desde un presente, dirigiéndose a alguien que ya no está:

Nunca habré de vengarme de ti por el silencio en que me tienes" (Robinson-Bent, 2010:93). A partir de allí, comienza la evocación de un pasado lejano que se carga de gran significación para la voz narrativa y que halla correspondencia en el elemento marino, ya que este comienza a personificarse y actuar como mensajero y testigo de este anhelo: "mientras solo trato de alcanzarte con mi voz; alcanzarte para mirar largamente tus ojos de mar sigiloso, contemplarte por muchas noches porque ya no me quedan palabras con que decirte nada, ya las he soltado todas al mar y al viento en busca de tus oídos (Robinson-Bent, 2010: 93).

Hay un corte después de una aparente disolución del vínculo amoroso: "[...] en tus labios ya se murió la palabra, sobre los míos agoniza el verbo" (Robinson-Bent, 2010: 98) y en el segundo fragmento observamos que el narrador comienza a establecer un juego temporal en el que alterna este pasado doloroso, que compara con un naufragio, con el anhelo de poder volver a reconstruir el vínculo y zarpar de nuevo, esperanza que reconoce inútil y frustrada: “¿qué rumbo tomaremos si el viento rehúsa propulsarnos? ¿en qué brújula buscaremos nuestro norte si nuestros caprichos nunca más resucitarán? ¿por qué faro nos guiaremos al puerto, si la luna ya no riela sobre nuestros mares?" (99). Aquí el mar sigue actuando como testigo, pero también como motor de la melancolía y es a partir de él que esta voz protagonista logra materializar sus sentimientos de nostalgia estableciendo analogías con los elementos naturales.

Posteriormente hay otro corte y surge un nuevo elemento geográfico recalcado por los teóricos Brathwaite y Glissant (2007): la montaña. Reaparece la evocación de ese pasado feliz que se conjuga con el anhelo de libertad: “[...] subíamos y coronábamos cumbres remotas sólo para señalar abajo las cosas de las cuales nos fugábamos, luego descendíamos con toda la humildad que nos cabía, las manos vacías y el espíritu rebosante de dicha" (Robinson-Bent, 2010: 101). Entre estos dos polos de la inmensidad, el mar y la montaña, el narrador logra comunicar al lector la hondura de sus pensamientos y es precisamente al escalar la montaña y enfrentarse a este temor de lo inmenso, y a la incertidumbre que suscita el vacío, lo que marca el fin de la relación entre los dos personajes del cuento: "Casi llegando al piso Sumarat, sin protesta, ni queja, ni maldiciones, procediste a deshacer el ascenso empañada en un humilde aire de vencido [...] Aunque nunca quisiste explicarme el porqué, tiempo después lo supe. Habías alcanzado la altura donde comienza a nacer 
el vértigo. Horror vacui, eso fue" (Robinson-Bent, 2010:100). Pero aquí este horror vacui no hace referencia sólo al momento de la subida, sino que funciona como elemento comparativo y estrategia poética que le facilita al protagonista-narrador comprender o justificar el abandono de su ser amado.

Hasta este momento se ha configurado un paisaje en el relato, el cual funciona como reflejo directo de las emociones y contradicciones que alberga el alma humana. Este actúa además como marca temporal, encontrando en el mar el comienzo, para posteriormente escalar hasta la cumbre de la remembranza. Y, en el último fragmento, descender de nuevo, pero a "un mar sin brisa" (Robinson-Bent, 2010:101), cambiando la focalización y combinando este pasado anhelado con un ensueño en futuro donde la mujer amada también sufre: "Y querrás hablarle de mis cartas sin poder acumular el suficiente coraje para hacerlo, porque jamás será nuestro aquel niño que tanto nos ha mirado desde el fondo sublime de todos los sueños" (102). La historia comienza y concluye en el mar, una forma temporal cíclica, pero a su vez inconclusa, ya que es un cierre hipotético tejido en el anhelo mismo del narrador.

Lo anterior coincide con lo enunciado por Brathwaite y Glissant: "En cualquier obra caribeña el ritmo responde de la manera lo más cercana posible al ritmo primordial del paisaje, a un verdadero juego de rayuela del paisaje. Éste crea el ritmo con el cual se tiene que vivir, el ritmo que se observa y que se ve, el ritmo con el que se sueña" (Brathwaite cit. en Phaf-Rheinberger, ed., 2007: 329). Por esta razón, como observábamos, esta poética marina logra trascender los espacios de la mera evocación. Esto podría tomarse como un simple artilugio estético, pero al adentrarnos en diferentes teorías sobre el pensamiento caribeño, como las propuestas por estos autores y extendida por Benítez-Rojo y Walcott, comprendemos que no se queda en el plano delo literario, sino que implica toda una ruptura con la forma en la que Occidente ha entendido y periodizado el tiempo.

En otras palabras, al adentrarse en el Caribe desde una visión europea, desde la otredad clausurada en la Historia, hallamos una zona de caos, que implica una pérdida de control y la incapacidad de fijar o apegarse a teleologías tan acostumbradas en el viejo continente. Pero a partir de la alteridad, de la comprensión de diferentes epistemologías, encontramos que este aparente caos, se rige por unas ciertas reglas internas, entre estas, que el paso del tiempo no lo marca el reloj, sino el mar: "Pero la cultura del Caribe, al menos el aspecto de ella que más la diferencia, no es terrestre sino acuática; una cultura sinuosa donde el tiempo se despliega irregularmente y se resiste a ser capturado por el ciclo del reloj o el del calendario. El Caribe es el reino natural e impredecible de las corrientes marinas, de las ondas, de los pliegues y repliegues, de la fluidez y las sinuosidades (Benítez Rojo, 1998: 51). Robinson- Bent lo refleja en la composición de sus obras como elemento estilístico: el mar comienza a ser la única marca de la temporalidad, abandonando la linealidad para comenzar a tener flujos y reflujos, como las mareas, en los que alternan constantemente el pasado, el presente y el futuro.

Es precisamente esta temporalidad marina la que condiciona y guía la vida de Ondina en "Regreso al alba". El mar cifra su comienzo y es en él donde ella debe vislumbrar su pretendido final: 
"Nadaba obedeciendo únicamente el impulso del mudo llamado de una voz que parecía haberla seguido fielmente en el agua desde siempre, desde cuándo aprendió a nadar a los cinco años" (Robinson-Bent, 1994: 9). Con el acontecer de los hechos, se nos dice que Ondina debe descifrar una vieja profecía que su abuelo Calvin había signado en un viejo cofre. En este momento, la observación del lecho marino cambia de faceta y vuelve a ser testigo y, a su vez proveedor de las claves para la resolución del misterio que, conjuntamente con un componente onírico, le aclara la verdad: “[...] allí volvió a ver el baúl flotando hacia ella, ya no en el océano, sino a la orilla del mar en la playa donde aprendió a nadar (16). Como vemos, la vida de Ondina está marcada en relación con el mar, resaltando constantemente la importancia de su aprendizaje del nado, habilidad que le permite adentrarse en lo insondable del misterio.

Pero el elemento marino no es solo cronología, también se personifica y se reviste de lo divino, comenzando a interactuar de maneras más determinantes en lo que le acontece a la protagonista: "[...] las personas realmente caras a ella habían sido arrebatadas por el mar como una cadena de fatalidades coincidentes" (Robinson-Bent, 1994:24). El mar se dibuja entonces dentro del relato como origen y final, el Alfa y Omega, cuestión que se comprende con la resolución de la profecía, anunciada al comienzo del relato, cuando "el hijo de todas las aguas, de todas las alboradas" es alumbrado en la inmensidad (Robinson- Bent, 1994: 24).

Podemos concluir parcialmente, con base en lo analizado en ambos relatos de Robinson-Bent, que es posible constatar cómo el paisaje muta de un simple decorado a un el elemento compositivo fundamental de la poética del autor y la forma en la que esta mirada derriba preconcepciones instauradas que clausuran y limitan al archipiélago al estatismo y la frivolidad. La estética de Robinson-Bent rescata esa ritmicidad del Caribe y se apropia de su territorio a partir de la comprensión de las múltiples facetas del mismo mar. Esta comprensión se expresa en una lengua heredada que, conjugada con la experiencia vital del hombre de puerto, logra construir, reflejar y resignificar la creolidad.

\section{Juan Ramírez Dawkins: historias sobre un territorio en disputa}

Desde el prefacio de su libro Short Stories, The Soldier Dem De Come and The Mango Tree, Ramírez Dawkins nos deja ver que sus cuentos serán incendiarios y que pretende decir lo que su pueblo no ha podido, para que otros escuchen. ${ }^{8}$ Ese apartado del libro es una declaración, un llamado a la justicia y la verdad, es un manifiesto del autor sobre sus intenciones con los relatos, sobre el por qué y para qué fue escrito. Denuncia, reclama, describe y reconoce asuntos que en la sociedad del archipiélago y del mundo han venido sucediendo y que él considera equívocos. En el prefacio, Ramírez Dawkins cuestiona los roles sociales y culturales que han estado regidos por la religión, ya sea bautista o adventista, que además se comporta como estamento de control

\footnotetext{
${ }^{8}$ Antes de entrar en el análisis de los relatos de Juan Ramírez Dawkins, es necesario reconocer algunos aspectos biográficos del autor que indican el carácter expresamente ideológico que singulariza su producción literaria. Ramírez Dawkins es un escritor providenciano que continúa viviendo aún en esa isla. Es representante de la comunidad raizal en asuntos étnicos en la Comisión Consultiva de Alto Nivel para el desarrollo de los derechos de las comunidades negras. Ha participado en grupos de trabajo para la prevención de la discriminación y protección de las minorías étnicas entre 1996 y 2002. Fue coordinador de la mesa de concertación entre el gobierno seccional y la comunidad raizal para el desarrollo del artículo 310 de la Constitución Política de Colombia, el cual contempla la expresión ideológica del pueblo raizal como un derecho de garantizar su supervivencia en forma digna y le da instrumentos para que, a partir de su propia visión, pueda construir puentes de prosperidad.
} 
Ana Elena Builes Vélez - Melissa Pérez Peña

por sobre el Estado. Ahonda además en las problemáticas de identificación y tensión social, al igual que hace una constante alusión al pasado de esclavización. "But one of most horrible procedures of the human race is what has been done to my ancestors, 355 years of slavery, hardheartness and the opression of mankind" (Dawkins, 1996: 9). Aunque el prefacio no es un relato no pierde el estilo poético del autor. Ofrece luces acerca del por qué cuenta lo que cuenta. Este apartado, particularmente, en conjunto con los agradecimientos y el memoriam del libro, solo están en inglés, no se traducen y no contienen elementos del kriol, lo que es bastante particular, teniendo en cuenta la estructura gramatical de toda la obra.

La escritura en inglés y kriol de los relatos de Ramírez Dawkins, junto con una traducción al español -de la cual él no se declara traductor y la cual conserva algunas fórmulas gramaticales de los idiomas originales- demuestran conocimiento del idioma español, pero a la vez la condición de este como un lenguaje aprendido por la escucha. Esta dimensión heterolingüe o multilingüe de sus relatos reafirma, en cierta medida, una tensión sociocultural que ha existido en la isla y con la isla. El libro de cuentos cortos The Soldier Dem De Come y The Mango Tree cuenta con varias características de lo que significa ser un sujeto insular: por un lado, está escrito por un raizal; por otro, debido a la poca difusión ha tenido escasa visibilidad y casi nula distribución en el continente $\mathrm{y}$, finalmente, presenta una estructura textual casi como un archipiélago mismo. Siguiendo la última idea, haremos referencia a algunos de los asuntos que están presentes en sus relatos, sobre los cuales vale la pena revisar en detalle y de los que surge esta afirmación.

Para este análisis partimos de la definición del Caribe como archipiélago, propuesta por Benítez-Rojo en la introducción de su libro La isla que se repite: "[...] el hecho de que las Antillas constituye un puente de islas que conecta, 'de cierta manera' [...] Suramérica con Norteamérica. Este accidente geográfico le confiere a toda el área, incluso a sus focos continentales, un carácter de archipiélago, es decir, un conjunto discontinuo (¿de qué?): condensaciones inestables [...] algas deshilachadas, [...] viajes de la significación" (Benitez Rojo, 1998: 16). Este archipiélago al igual que otros puede verse como una isla que se "repite" a sí misma. Esta definición nos permite no sólo la comprensión de la insularidad sino, a su vez, entender la manera en que los relatos de Ramírez Dawkins se configuran entre esos espacios, esas voces deshilachadas, diferentes conexiones y realidades superpuestas de los raizales y los Panyas.

Como lo mencionamos en el apartado sobre el Caribe, esta región se encuentra en una constante construcción que se edifica desde la imaginación. Este acto, era en un principio un proceso colectivo, de la tribu, un proceso oral, luego las historias fueron escritas, pero el poeta narrador de la isla, se enfrenta a la lengua que escucha y que le cuesta escribir. Según Walcott, esto sucede aún hoy, porque carece de símbolos y porque cuanto más aproxima el poeta su mano y su palabra a las precisas inflexiones de la lengua interior y a las sutilezas de su oído, más caótico es el aspecto de los símbolos en la página, más reducido el dialecto regional, más excéntrica la representación que el poeta hace de aquel, por lo que la función del primero sigue siendo la tradicional de filtro y purificador, sin perder en ningún momento el tono y la fuerza del habla común cuando emplea 
los jeroglíficos, los símbolos o el alfabeto de la lengua oficial (Walcott, 2018: 68). En Ramírez Dawkins es posible encontrar estas sutilezas y ese caos del que habla Walcott. Para ejemplificar, citamos a continuación un fragmento del cuento The Mango Tree en inglés, kriol y en español:

The panya had discovered the native way of living. They knew that native don't worry too much about people getting some of the mangoes for food. Natives like to share so much that we share out ourselves.

"Poor people dem," said Liza. "They also have need like us. Let us dem get some of the mangoes" (Dawkins, 1996: 26. Negritas en el original).

Los Panyas habían descubierto la forma de vivir de los nativos. Ellos sabían que los nativos no se preocupaban mucho por si la gente se lleva los mangos para comérselos. A los nativos les gusta, les encanta compartir tanto que en la repartición se quedaron sin nada.

"Pobre gente" dijo Liza "Ellos también tienen necesidades como nosotros. Permitámosle que se lleven algunos mangos" (Dawkins, 1996: 57).

Se puede observar acá la manera en que los códigos de la naturaleza no están prefijados, ni limitados. En este caso, los mangos actúan como sinécdoque de la relación del nativo con el territorio, entendiendo a su vez la tierra como la proveedora y unificadora de las relaciones humanas, la cual debe ser compartida. Acudiendo a Benítez-Rojo, y entendiendo que, para él, los "pueblos del Mar" representan y expresan sus intenciones de acabar con la violencia social, a manera de conjuro, al remitirse a lugares poéticos, que representan ese lugar en caos, ese territorio en pugna. En ambos cuentos, Ramírez Dawkins muestra y denuncia además el caos al que son sometidos los nativos en su lugar seguro, cuando son obligados a desplazarse y a migrar, porque su lugar es un punto estratégico para el gobierno:

An official and a civilian who were at the gate started walking towards him. When they reached Danny Hooker, the civilian said to him "Good morning, Mr. Hooker." Without even waiting for an answer, he kept on addressing him, "As you can see Mr. Hooker, these people asked me to explain to you that, according to the law, you and your family will have to move your house and all your belongings. They will give you a good amount of money so you can buy another piece of land somewhere (Dawkins, 1996: 18).

La problemática del destierro y del despojo que se trata de múltiples maneras en ambos cuentos, The Mango Tree y The Soldier Dem de Come, en los cuales el autor deja ver no solo la realidad, si no su posición frente a estas situaciones a las que se ven sometidas las comunidades raizales.

El uso del español, el inglés y el kriol en los títulos y los textos mantiene en tensión el asunto del mestizaje y su relación con las lenguas. Es quizás por esto que la obra de Ramírez Dawkins parece haberse quedado olvidada, guardada y encerrada dentro de la isla. Esto debido a la escasez de lectores fuera de la Isla, ya que, al interior de Colombia se desconoce el kriol y se ha optado por la 
Ana Elena Builes Vélez - Melissa Pérez Peña

formación de estándares estéticos basados en el monolingüismo. La recepción de un escritor como Ramírez Dawkins, que se resiste a escribir sólo en español, parece estar mediada por el escaso reconocimiento de otras posibilidades lingüísticas y de lenguas menores y olvidadas como el kriol. Ambos cuentos tienen dos versiones. La versión en inglés-kriol tiene unas características particulares reflejadas en una estructura que sugiere una cercanía a la oralidad. Adopta no solo las formas del diálogo, sino también elementos gramaticales propios de la comunicación hablada. La traducción al español presenta algunas características importantes: la estructura gramatical conserva elementos del inglés, hay errores ortográficos intencionales y no es posible identificar, en algunos elementos, si su uso es debido a una intencionalidad estilística del autor para guardar fidelidad con el texto o por alguna otra razón mediada por la lengua original (inglés-kriol).

La estructura de los cuentos está basada principalmente en la narración de hechos. No hay grandes rodeos estéticos ni la intencionalidad de producir imágenes complejas, sino, por el contrario, de centrarse principalmente en el acontecer a modo de denuncia o reflexión sobre situaciones sociales específicas: la isla como Puerto libre, la tensa situación entre Colombia y Nicaragua, y la presión del Estado colombiano por la tenencia de la tierra, solo por mencionar unos cuantos:

Then, the interpreter continued telling Mr. Hooker that the presence of the military on the Island was to give us protection against a possible invasion from the Nicaragua Government and they wanted this piece of land so they could establish their general headquarters [...] "Tell the soldiers that $I$ have been living here for more than sixty years. This is my property inherited from my ancestor [...] this only happen in the communist countries where the state tale away land from families. Tell them that we and the people from Nicaragua have lived in peace for a long time" (Dawkins, 1996: 18).

En los relatos de Ramírez Dawkins hay una referencia directa a los asuntos socio-políticos de la época en el país y las formas como estos asuntos afectaban de manera directa las poblaciones más aisladas y donde menos presencia había del gobierno. Por lo anterior, la isla aparece bajo su nombre y además se carga de constantes referencias culturales, que buscan visibilizar y rescatar prácticas que pueden ser percibidas por el autor como en peligro, igualmente con el uso del kriol:

After singing, she started drifting, remembering her childhood when the sailboats arrived from Colon with the rolls of silky cloth, high-heel shoes [...] the concerts she participated in acting as the Queen of Sheeba with tremendous success; the duppy story tell by Grandpa and Grandma; $[\ldots]$ the moonshine baby; the cane mill where she escaped at times with her brothers [...] She also remembered the hard work done and that things could be worse (Dawkins, 1996: 17).

Se evidencia una vez más el sueño y el recuerdo de las tradiciones y la posibilidad de perderlas. La idea de tener que trabajar porque todo aquello que les es propio se mantenga y por el pedazo de tierra que fue heredado -pero que saben que igual perderán- está presente en ambos relatos del autor. 
The soldier dem the come es un relato que narra la historia de una familia que se ve enfrentada al desplazamiento y desalojo de su hogar -heredado durante generaciones- a manos del ejército del país, que no habla su misma lengua y que se ve obligado a llegar a la casa de la familia con un intérprete, para que la comunicación sea efectiva. El relato inicia con un sueño premonitorio de uno de los hermanos: que los soldados vienen a casa mientras ellos están lejos pescando. La duda y ansiedad que acompañan a uno de los hermanos durante el día, genera una atmósfera tensa que Ramírez Dawkins relata a través del paisaje y el mar. La llegada de nuevo a la costa, la cercanía con la casa aumenta esa sensación y el caos comienza:

While they were laughing, they saw someone running towards them. It was their sister Estebana. She was waiving and calling them. When she was about ten meter distance from them, she shouted out, "Di soldier dem de come. Twenty a de mina de yard. Come quick. Come help Ma. Come!" (Dawkins, 1996: 14).

En este relato se evidencian las diferentes maneras de relacionarse de la comunidad con los otros. El ejército -que representa la Nación-, los nicaragüenses, los vecinos, la familia, representan cada uno una relación distinta, mediada siempre por las tradiciones, el territorio y la lengua. Cada tensión que se relata es reafirmada y recontada en los diálogos, se repite, viene y se va, como las olas del mar. Al final, la familia se ve obligada a salir con la casa entera. Mr. Hooker sale abrazando la foto de su padre, con la certeza de haber perdido no solo su casa, sino la tierra, sus tradiciones, su pasado, su futuro, su vida entera:

Danny Hooker was put into the truck and taken to jail. Five days after, he was release. But his biggest surprise was that when he reach back to home, he found his house taken down and all his belongings were over the yard. Danny stopped the truck that was passing, then put his things $[\ldots]$ He get on his mare, holding his parent's photograph and start behind them. Who knows heading where... who knows" (Dawkins, 1996: 19).

The Mango tree narra la relación entre los habitantes nativos de la isla, y los nuevos dueños de la tierra y los cultivos. Relata una tensión social, debido a la cual aparece una nueva denominación para los recién llegados: panya, lo que declara, pone de manifiesto, una fractura social y una dualidad frente a estas nuevas relaciones:

Native families don't pay much attention to mango pickers. But, you can't do this with the new owners. Their land is well-fenced and with sign boards telling you THIS IS PRIVATE PROPERTY NO TRESPASSING. The native people still keep their land without a fence. We respect each other boundaries, separate only by trees that was previously planted and agreed. You can still pick up mangoes (Dawkins, 1996: 20).

La idea de la privacidad y el respeto entre nativos y los nuevos habitantes es diferenciada. Para los nativos los límites ya han sido establecidos y acordados naturalmente por lo que no es necesario materializarlos, en consecuencia, esta demarcación de la propiedad privada, realizada por los recién 
Ana Elena Builes Vélez - Melissa Pérez Peña

llegados, es entendida como un irrespeto.

Ya hemos llamado la atención acerca del carácter del kriol como una lengua primordialmente oral, lo que a su vez facilitaba que los intercambios económicos fueran arreglados principalmente a partir del respeto de la palabra dada. Con las migraciones de los habitantes del interior del país hacia la isla, el Estado comienza a permear y casi a abusar de la propiedad de la tierra, cuestión facilitada por el carácter informal con que los isleños trazaban las relaciones políticas y económicas. Esto se evidencia en el relato en relación con las relaciones de intercambio de los productos de la isla como el mango y el coco. El mango se puede coger de todos los árboles de las casas de los nativos, pero no de las de los nuevos habitantes porque estas están cercadas. Dicha cuestión evidencia, nuevamente, una fractura, una tensión. Los pobladores nativos no sienten la necesidad de delimitar sus casas, los límites ya están dados por la tierra misma y la cercanía con sus vecinos es resultado de una relación mediada por la confianza y el respeto a la palabra. Sin embargo, este asunto se dificultaba precisamente por las diferencias idiomáticas entre el inglés, el kriol y el español que truncaban la comunicación:

She stood up from worship, the asked me how much she owed me. I told her that between the bottles and the mangoes it was half -dollar [...] I give her thanks and start walking for my home when tow little Spanish boy came up calling Coco and asking her if she had mango for sale. [...] She couldn't talk Spanish but she could communicate with them, making signs (Dawkins, 1996: 37).

En ambos relatos, Ramírez Dawkins nos está relatando la historia con " $\mathrm{h}$ " minúscula del archipiélago. Nos cuenta cómo, casa a casa, la comunidad ha sido desplazada, ha sido obligada a dejar a un lado sus tradiciones, a olvidar sus raíces y a tomar otros rumbos por el bien común de un país que no reconocen como suyo. Relata dialógicamente, en tres lenguas distintas, la cotidianidad de la isla, con el mar, la arena y las palmeras como testigos silenciosos de los vejámenes a los que se ven sometidas las familias isleñas.

\section{Los imaginarios poéticos desde y hacia el archipiélago}

Las diferencias en las construcciones literarias de Robinson-Bent y Ramírez Dawkins están en función del uso del lenguaje y las formas de la narración. Mientras el segundo está mucho más cercano a la oralidad y utiliza diferentes estructuras gramaticales e idiomas, el primero narra a partir de la conjunción de sus herencias. Sin embargo, ambos intentan hacer una lectura de las vivencias, emociones, temores, anhelos y sueños que se tejen al interior del territorio insular. Ramírez Dawkins, por sus propósitos políticos, utiliza el artefacto literario como posibilidad o puente de reconocimiento de tradiciones olvidadas y como mecanismo de denuncia frente a las situaciones que aquejan a su pueblo. Robinson-Bent, por su parte, apela a poetizar a partir del paisaje que le circundó, el mar y las montañas, y cómo en este se tejen historias de profunda nostalgia y melancolía. 
Ambas formas de estructuración narrativa nos permiten confirmar las teorizaciones de los diversos pensadores caribeños que hemos considerado aquí, en especial aquellas que plantean al meta-archipiélago como un conjunto de resonancia de varias voces, la conjunción de la polifonía y la diversidad. El territorio no puede ser clausurado por una sola forma de percibirse y así mismo, la creolidad no puede estar fijada a elementos como la piel o la lengua, sino que debe expandirse y comprenderse a partir de todo un enraizado epistemológico que tiende puentes de unión, pero no con ánimo unificador sino, por el contrario, reconociendo las similitudes, pero también teniendo presente las particularidades. Podemos ver, entonces, cómo ambos autores, aunque recurren a diferentes formas lingüísticas y construcciones poéticas, logran configurar una idea del archipiélago que entra en constante tensión con los imaginarios tejidos desde Europa. La nostalgia, el desarraigo, la soledad, las tensiones sociales, la desaparición de un pueblo y sus tradiciones se contrastan con las fotografías de la fiesta caribeña, del jolgorio y la borrachera que venden las agencias de turismo.

\section{BIBLIOGRAFÍA}

Acosta Peñaloza, C. E. (2007). Las historias regionales de la literatura y la actualización del pasado literario. En Leer la historia: caminos a la historia de la literatura colombiana (pp. 163186). Bogotá: Universidad Nacional de Colombia.

Bachelard, G. (1993). El agua y los sueños: ensayo sobre la imaginación de la materia. México: Fondo de Cultura Económica.

Banceline, C. (2010). Lenito Robinson-Bent, un hallazgo ausent. En L. Robinson-Bent, Sobre nupcias y ausencias y otros cuentos (pp. 9-20). Bogotá: Ministerio de Cultura.

Benítez-Rojo, A. (1998). La isla que se repite. Barcelona: Editorial Casiopea.

Bernabé, J., P. Chamoiseau y R. Confiant, (2011). Elogio de la creolidad. Bogotá: Editorial Pontificia Universidad Javeriana.

Botero, J. (2007). Oralidad y escritura en la Isla de San Andrés. Universitas Humanística, (64), 275-289.

Clemente, I. (1994). El Caribe Insular: San Andrés y Providencia. En C. Borrego, I. Clemente, N. del Castillo, A. Múnera, E. Posada, \& A. Sourdis, Historia Económica y Social del Caribe Colombiano (pp. 331-375). Bogotá: Ediciones Uninorte.

Enciso, P. (2004). Los hilos que amarran nuestra historia. San Andrés: NAFASD.

Phaf-Rheinberger, Ineke, ed. (2007). El lenguaje-nación y la poética del acriollamiento. Una conversación entre Kamau Brathwaite y Édouard Glissant. Trad. y notas Carolina Benavente Morales. Literatura y Lingüística, (19), 311-329. 
Ana Elena Builes Vélez - Melissa Pérez Peña

Glissant, E. (2002). El discurso antillano. Caracas: Monte Ávila Editores.

Maglia, G. (2017). Paisaje, identidad y nación en el Caribe poscolonial: Edouard Glissant y Dereck Walcott. La Palabra, (31), 88 - 99.

Martínez-San Miguel, Y. (2003). Caribe two ways: cultura de la migración en el Caribe insular hispánico. Río Piedras: Ediciones Callejón.

Prescott, L. (1996). Perfil histórico del autor afrocolombiano: problemas y perspectivas. America Negra, (12), 104-125.

Ramírez Dawkins, J. R. (1996). Short Stories. The soldier dem de come and The mango tree. Santiago de Cali: Editorial.

Robinson-Bent, L. (1994). Las casas huidizas y otros cuentos sobre fugas. Bogotá: Colcultura.

Robinson-Bent, L. (2010). Divagaciones para una carta a Nereida del Mar. En Sobre nupcias y ausencia y otros cuentos (pp. 93-102). Bogotá: Ministerio de Cultura.

Tulcan, D. P. (2016). De isleños a sanandresanos: la construcción de identidades en San Andrés Isla vista desde las novelas No Give Up, ;Maan! de Hazel Robinson Abrahams y Los pañamanes de Fanny Buitrago (Tesis de doctorado, Universidad Nacional de Colombia-Sede Bogotá).

Valle, M. del (2016). Perspectivas críticas sobre la literatura en San Andrés Isla, Colombia. En Y. Solano, Cambios sociales y culturales en el Caribe colombiano: perspectivas críticas de las resistencias (pp. 179-208). Bogotá: Universidad Nacional de Colombia 